\title{
VARIATION IN PLANT DEVELOPMENT WITHIN A POPULATION OF LOLIUM MULTIFLORUM
}

\author{
K. J. R. EDWARDS and Y. A. EMARA* \\ Welsh Plant Breeding Station, Plas Gogerddan, Aberystwyth
}

Received 4.iv.69

\section{INTRODUCTION}

A PROGRAMME for breeding a new variety of a cultivated crop obviously depends on the amount and nature of genetic variation within the base population. In inbreeding species the plant breeder has to create a variable population by producing a segregating generation, usually on $F_{2}$, from a hybrid between two inbred lines. In outbreeding species, on the other hand, existing varieties will be genetically variable and may offer possibilities of improvement within such populations.

Lolium multiflorum (Italian ryegrass) is a commercially important outbreeding grass species. Populations are likely to be genetically variable and this variability may be directly exploitable without creating new populations by hybridisation. The main advantage of improvement by breeding within a population is that the base population is likely to be reasonably well adapted to certain environments whereas a novel population may not be so, even if the two parental populations were.

It seemed worth while, therefore, to attempt to assess the variation within a population to see to what extent improvement within a population of L. multiflorum is possible. In addition, certain populations of this species are sami-natural, having undergone perhaps 100 generations of production for commercial seed with no conscious selection and no inbreeding. Beddows (1953) described the system of management under which such populations have been grown in N. Ireland. The seed is sown in May under a cover crop of oats; after the oats have been harvested the grass may be grazed that autumn; and in the following summer a seed crop is taken. A portion of this seed is retained to provide the next seed crop while the rest is sold for production of swards of ryegrass. In view of this known history of the population we thought that the analysis of its genetic variation would be of interest, in the light of the arguments of Mather (1943, 1960) and Breese and Mather (1960) that the genetic architecture of a character in a population will depend upon the nature of the selection to which the population has been subjected in the past.

Previous work on Lolium has been largely concerned with variation between populations (Thomas, 1967) or within small selected groups of plants which were the potential basis of a new variety (Beddows et al., 1962). Cooper $(1959 b)$ has demonstrated that a small sample of a population of $L$. perenne can contain a tremendous amount of genetic variation for flowering time, which can be released by directional selection, while subsequent work (Cooper and Edwards, 1961; Edwards and Cooper, 1964) has shown the existence of appreciable genetic variation, as demonstrated by directional

* Present addresses: Department of Genetics, Milton Road, Cambridge, and Department of Biology, Memorial University, St. John's, Newfoundland, Canada. 
selection, for leaf size and rate of leaf appearance within populations of both $L$. multiflorum and $L$. perenne.

This paper reports a study of the variation for a large number of characters within a single population of $L$. multiflorum. The analysis of the variation within a population requires the assessment of components of variance. The more such components it is thought desirable to estimate the more complicated becomes the design of the experimental mating system. If there is an operational limit to the number of families which can be handled, a complicated design with multiple matings leads to a concomitant reduction in the size of the sample of parents taken from the population. Thus there is a conflict between the amount of information obtained and the size of the sample on which it is based. Kearsey (1965) has discussed this problem in relation to a number of different experimental designs. For our purpose the most appropriate design seemed to be the one proposed by Comstock and Robinson (1952) and generally known as North Carolina design II. In this design all possible matings are made between the individuals in two groups of plants, but no matings are made within groups and in this way it differs from a diallel cross. Individuals are assigned to the groups at random and there may be several pairs of such goups, that is the experiment will be replicated. Such a system allows the estimation of genetic and environmental variances and the partitioning of the genetic into additive and non-additive components.

\section{Experimental details}

\section{(i) Mating design and analysis}

Sixty plants were sampled at random from a single commercial population of Lolium multiflorum derived originally from N. Ireland. The 60 plants were randomised into 15 sets of 4 each. Within each set they were assigned at random into 2 groups of 2 . Crosses, including reciprocals, were made within each set between the 2 groups in all combinations. Thus within a set there were 4 crosses which, with reciprocals, produced 8 families. Over all 15 sets there were 120 families. Crosses were made using the automatic pollination technique of Jenkin (1931) without emasculation.

The 120 families were grown in boxes in greenhouses in a complete randomised block layout with 2 replicates. Within each block a row of 5 individual plants of each family was grown. The data was analysed statistically in three different ways, as shown in table 1. Analysis A was used to determine the overall importance of genetic variation (crosses item) and reciprocal differences. If the reciprocal differences item was not significantly large, then the genetic variation could be analysed by Analysis B and the components of variance estimated and analysed as follows (Kearsey, 1965):

$$
\begin{aligned}
& \sigma_{m}^{2}=\sigma_{f}^{2}=\frac{1}{8} D_{R} \\
& \sigma_{m f}^{2}=\frac{1}{16} H_{R} \\
& \sigma_{w}^{2}=\frac{1}{4} D_{R}+\frac{3}{16} H_{R}+V_{E} .
\end{aligned}
$$

In a random mating population the total genetic variance $V_{G}$ will be composed as follows:

$$
V_{G}=\frac{1}{2} D_{R}+\frac{1}{4} H_{R}
$$


In the absence of non-allelic interactions, $\frac{1}{2} D_{R}\left(=V_{A}\right)$ will be the genetic variance due to additive effects and $\frac{1}{4} H_{R}\left(=V_{D}\right)$ will be that due to dominance deviations. Non-allelic interactions may be expected to cause a bias

\begin{tabular}{|c|c|c|c|}
\hline \multicolumn{4}{|c|}{$\begin{array}{c}\text { TABLE } 1 \\
\text { Analyses of variance }\end{array}$} \\
\hline Analysis & Item & $\begin{array}{l}\text { Degrees of } \\
\text { freedom }\end{array}$ & Expectation of mean square \\
\hline A & $\begin{array}{l}\text { Families (in sets) } \\
\text { Crosses (in sets) } \\
\text { Reciprocals within crosses } \\
\text { Family } \times \text { block interaction } \\
\text { (in sets) } \\
\text { Within families } \\
\text { Sets } \\
\text { Blocks (in sets) }\end{array}$ & $\begin{array}{r}105 \\
45 \\
60 \\
105 \\
960 \\
14 \\
15\end{array}$ & \\
\hline B & $\begin{array}{l}\text { Males (in groups) } \\
\text { Females (in groups) } \\
\text { Males } \times \text { females interaction } \\
\text { Between groups in sets } \\
\text { Family } \times \text { block interaction } \\
\text { Within families } \\
\text { Sets } \\
\text { Blocks (in sets) }\end{array}$ & $\begin{array}{r}30 \\
30 \\
30 \\
15 \\
105 \\
960 \\
14 \\
15\end{array}$ & $\begin{array}{l}\sigma_{w}^{2}+10 \sigma_{m f}^{2}+20 \sigma_{m}^{2} \\
\sigma_{w}^{2}+10 \sigma_{m f}^{2}+20 \sigma_{f}^{2}+20 \sigma_{m a t}^{2} \\
\sigma_{w}^{2}+10 \sigma_{m f}^{2} \\
\sigma_{w}^{2}\end{array}$ \\
\hline C & $\begin{array}{l}\text { Parental effects } \\
\text { Parental interactions } \\
\text { Maternal effects } \\
\text { Maternal interactions } \\
\text { Between groups in sets } \\
\text { Family } \times \text { block interaction } \\
\text { Within families } \\
\text { Sets } \\
\text { Blocks (in sets) }\end{array}$ & $\begin{array}{r}30 \\
15 \\
30 \\
15 \\
15 \\
105 \\
960 \\
14 \\
15\end{array}$ & $\begin{array}{l}\sigma_{w}^{2}+10 \sigma_{r}^{2}+20 \sigma_{g}^{2}+20 \sigma_{m a t}^{2}+40 \sigma_{g}^{2} \\
\sigma_{w}^{2}+10 \sigma_{r}^{2}+20 \sigma_{g}^{2} \\
\sigma_{w}^{2}+10 \sigma_{r}^{2}+20 \sigma_{m a t}^{2} \\
\sigma_{w}^{2}+10 \sigma_{r}^{2} \\
\sigma_{w}^{2}\end{array}$ \\
\hline
\end{tabular}

The variance terms have the following interpretations:

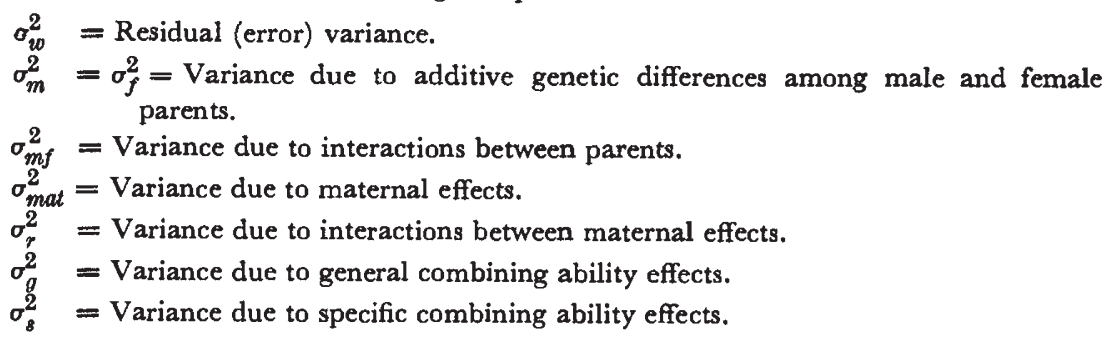

in each but to be mainly included in the dominance term. Thus the estimates obtained of $\frac{1}{2} D_{R}$ and $\frac{1}{4} H_{R}$ can be thought of as the additive and nonadditive (dominance plus interactions) genetic variances respectively.

If the reciprocal differences item is significant the interpretation and estimation of the genetic parameters becomes more complex. Firstly it is then necessary to ask if the reciprocal differences are due to maternal effects 
(either inherited or nutritional). This can be determined: (i) by testing the females item against the males item in Analysis B, for a maternal effect will inflate the former: and (ii) by testing the significance of the maternal and maternal interaction items in Analysis C. These latter tests will also determine whether the maternal effects, if present, are additive or interactions. If they are additive the females item in Analysis B cannot be used and the genetic parameters must be estimated from $\sigma_{m}^{2}$, $\sigma_{m f}^{2}$ and $\sigma_{v}^{2}$. But if the maternal effects are interactions the males $\times$ females item in Analysis B will be inflated and $H_{R}$ must be estimated from the parental interactions item in Analysis C. The relationships between the components obtained from Analyses B and $\mathrm{C}$ is as follows:

(i) if no maternal effects

1. $\left(\sigma_{m}^{2}+\sigma_{f}^{2}\right) / 2=\sigma_{g}^{2}=\frac{1}{8} D_{R}$

2. $\sigma_{m f}^{2}=\sigma_{s}^{2}=\frac{1}{16} H_{R}$

(ii) if maternal effects present

1. $\left(\sigma_{m}^{2}+\sigma_{f}^{2}\right) / 2=\sigma_{g}^{2}+\sigma_{m a t}^{2}$

2. $\sigma_{m f}^{2}=\sigma_{s}^{2}+\sigma_{r}^{2}$.

If no maternal effects are present, the components from Analysis B have been used to estimate the genetic parameters because they have more degrees of freedom.

The assumptions involved in making these interpretations are:

1. Regular diploid behaviour at meiosis.

2. No multiple allelism.

3. No correlation of genotypes at different loci. This implies either no linkage between genes affecting the character or, if linkage exists, that there is linkage equilibrium in the population.

4. No non-allelic interaction.

The first assumption is almost certainly satisfied since L. multiflorum is a diploid $(2 n=14)$ which regularly forms seven bivalents at meiosis. Linkage equilibrium may occur or be fairly closely approximated since in the natural population mating appears to be at random. On the other hand natural selection may have produced linkage disequilibrium, especially if it is stabilising selection which is likely to favour repulsion linkages (Mather, 1943). Thus linkage disequilibrium is quite likely present and multiple allelism and non-allelic interaction are almost certainly present. These factors need to be borne in mind when interpreting the results. Another assumption commonly made in biometrical genetics is that there are no maternal effects. As this experiment includes reciprocal crosses, maternal effects can be detected and their contribution to phenotypic variation estimated.

\section{(ii) Measurements}

The types of character measured are essentially similar to those reported by Cooper (1959a), Cooper and Edwards (1961) and Edwards and Cooper (1963), where details of methods of measurements can be found. The characters fall into three groups: 
(a) Seedling leaf characters (on main shoot):

(i) Leaf dimensions: The length and width of the third and sixth leaves on the main shoot. From these dimensions the areas of the two leaves were computed.

(ii) Rates of leaf production: The dates of appearance of the ligules of leaves 2, 3, 5 and 6 were recorded, from which the rates of leaf production over certain intervals were computed and expressed as the rate of leaf appearance per day.

(b) Whole plant characters:

(i) Number of tillers (shoots) per plant at certain stages or dates From these data, rates of tillering were computed for each plant.

(ii) Total dry weight of the shoot three months after sowing.

(c) Flowering characters:

(i) Date of emergence of first inflorescence.

(ii) Plant height: height of tallest spike.

(iii) Number of inflorescences per plant.

The first two groups of characters were recorded on plants grown in boxes of soil in a greenhouse. The flowering characters were recorded the following year after the plants had been transplanted into a field using a similar experimental layout but after re-randomisation of the rows within each block.

\section{Results}

For all characters in which the Type A Analysis showed the reciprocal differences item mean square to be significantly larger than the "error" (family $\times$ block interaction), the females item in the Type B Analysis were larger than the males item; thus it was concluded that all reciprocal differences which occurred were maternal in origin. For these characters the Type C Analysis was used to estimate both genetic and maternal components of variation.

In the Type B and C Analyses the various mean squares were tested in variance ratio tests in a heirarchical way. Thus in the Type B Analysis the combined males and females mean square was tested against the males $x$ female mean square if the latter were itself significantly larger than the error mean square $($ at $\mathrm{P}<0 \cdot 05)$; otherwise it was tested directly against the error. The probability levels presented are based on such variance ratio tests.

\section{(i) Seedling leaf characters}

Table 2 shows that for this group of characters reciprocal differences were important only for leaf 3 . For leaf 3 the significance of the crosses item compared to the reciprocal differences item indicates that genetic variation existed. For all other characters in this group the crosses item accounted for all the variation between families.

For length of leaf 3 the reciprocal differences were due to additive maternal effects while for width they were interactions (table 3 ). The genetic 


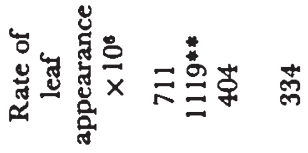
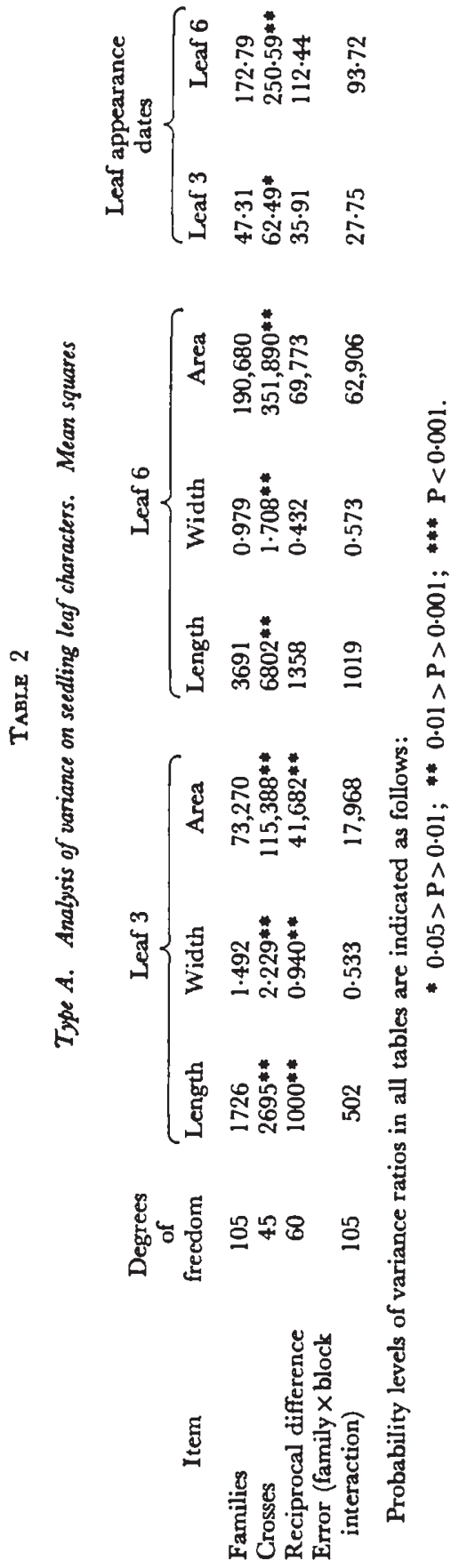
variation appeared to be largely non-additive although length of leaf 3 gave evidence of additive effects also.

For leaf 6 measurements and leaf appearance data the Type B Analysis mean square are shown in table 4 . All leaf 6 characters show a significantly large males $\times$ females item, with additive effects showing for length and area also. The leaf appearance characters on the other hand show only additive effects.

TABLE 3

Type C. Analysis of variance for leaf 3 measurements Item $\quad \begin{gathered}\text { Degrees of } \\ \text { freedom }\end{gathered}$

Parental effects

Parental interactions

Maternal effects

Maternal interactions

Error

30
15
30
15
105

Length Width

$3236^{*} \quad 2 \cdot 277$

$1613^{* * *} \quad 2 \cdot 134$

$1265^{* *} \quad 0.698$

$609 \quad 1 \cdot 256^{* *}$

$502 \quad 0.533$
Area

12,9097

$87,972 *$

41,840

$33,026^{*}$

17,968

The estimates of components of the population variance and of certain genetic parameters which can be derived from these statistics are presented in table 5. Where maternal effects (additive and interactions) were detected they account for less than 10 per cent. of the total population variance. The relationship between the genetic variance and the total phenotypic variance is expressed in two ways: heritability in the broad

TABLE 4

Type B. Analyses of variance for leaf 6 and leaf appearance characters

\begin{tabular}{|c|c|c|c|c|c|c|c|}
\hline \multirow[b]{2}{*}{ Item } & \multirow{2}{*}{$\begin{array}{l}\text { Degrees } \\
\text { of } \\
\text { freedom }\end{array}$} & \multicolumn{3}{|c|}{ Leaf 6} & \multicolumn{2}{|c|}{$\begin{array}{l}\text { Leaf appearance } \\
\text { dates }\end{array}$} & \multirow{2}{*}{$\begin{array}{c}\text { Rate of leaf } \\
\text { appearance } \\
\times 10^{8}\end{array}$} \\
\hline & & Length & Width & Area & Leaf 3 & Leaf 6 & \\
\hline $\begin{array}{l}\text { Males }+ \text { females }) / 2 \\
\text { Males } X \text { females } \\
\text { Irror }\end{array}$ & $\begin{array}{r}60 \\
30 \\
105\end{array}$ & $\begin{array}{l}4942^{* *} \\
2166^{* *} \\
1019\end{array}$ & $\begin{array}{l}1 \cdot 082 \\
1 \cdot 059^{* *} \\
0.573\end{array}$ & $\begin{array}{c}243,606^{*} \\
139,420^{* *} \\
62,906\end{array}$ & $\begin{array}{l}49 \cdot 83^{* *} \\
39 \cdot 09 \\
27 \cdot 75\end{array}$ & $\begin{array}{l}208 \cdot 12^{* * *} \\
123 \cdot 14 \\
93 \cdot 72\end{array}$ & $\begin{array}{l}953^{* * *} \\
451 \\
334\end{array}$ \\
\hline
\end{tabular}

sense $\left(\frac{V_{G}}{V_{P}}\right)$, and heritability in the narrow sense $\left(\frac{V_{A}}{V_{P}}\right)$. The total genetic variance accounts for between one-third and two-thirds of the total phenotypic variance for leaf dimension characters, this proportion being higher for leaf length than for width and higher for leaf 6 dimensions than for those of leaf 3. Of this total genetic variance for leaf dimensions, the additive component constitutes roughly one-third. For the dates of leaf appearance characters the broad heritability is about one-quarter with a tendency for this to rise with age. The proportion of this total genetic variance which is additive rises from one-third to one-half with age. Rate of leaf appearance has a broad heritability of 37 per cent. of which more than half is additive.

\section{(ii) Whole plant and adult plant characters}

In this group, the only character in which there were no reciprocal differences, was flowering time (table 6). The genetic variance for flowering time was largely additive (table 7 ). The nature of the reciprocal differences 


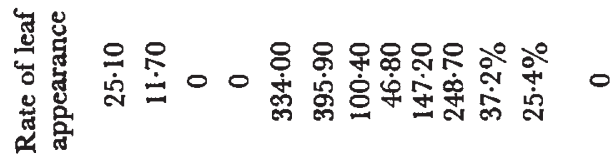

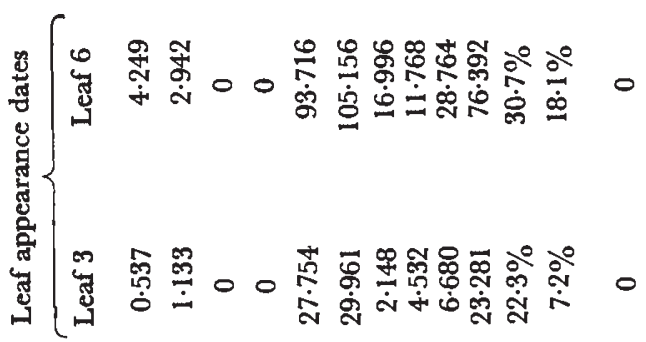

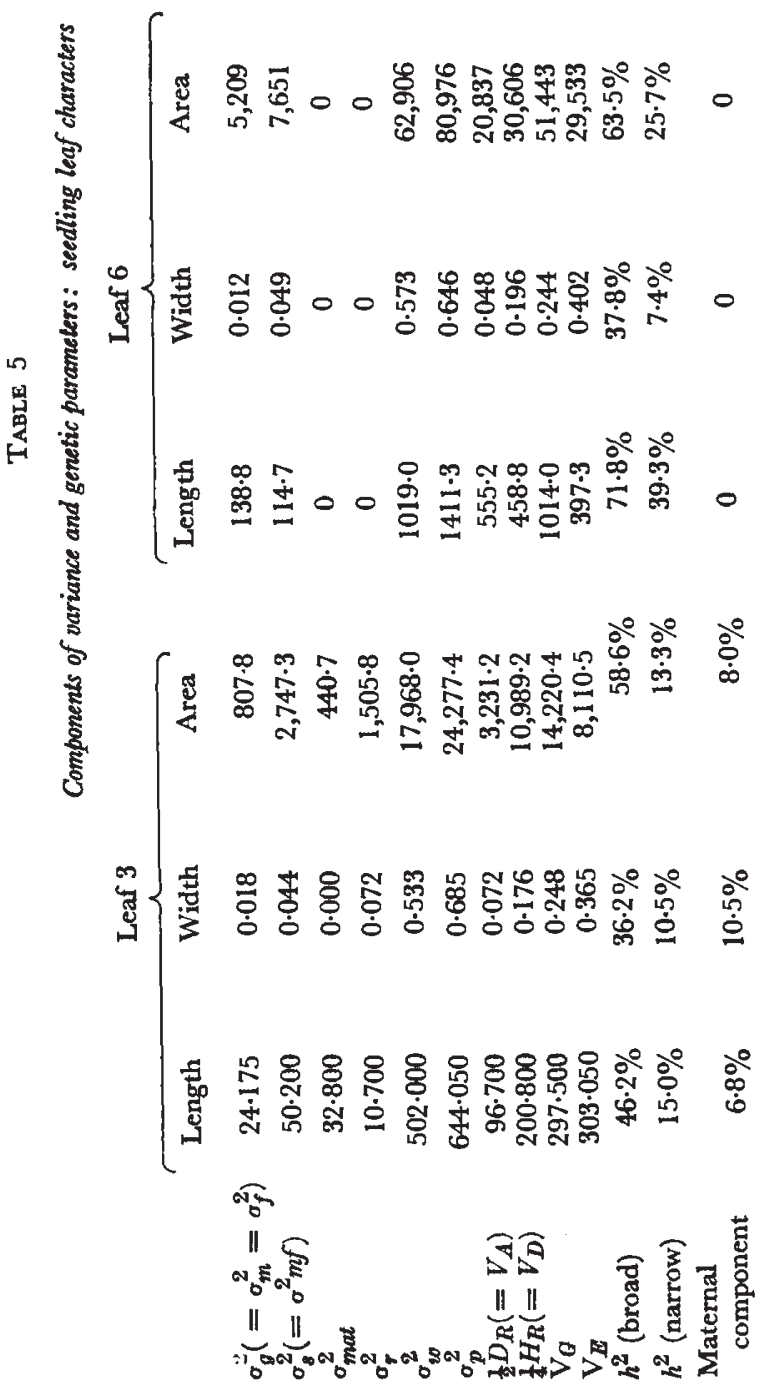




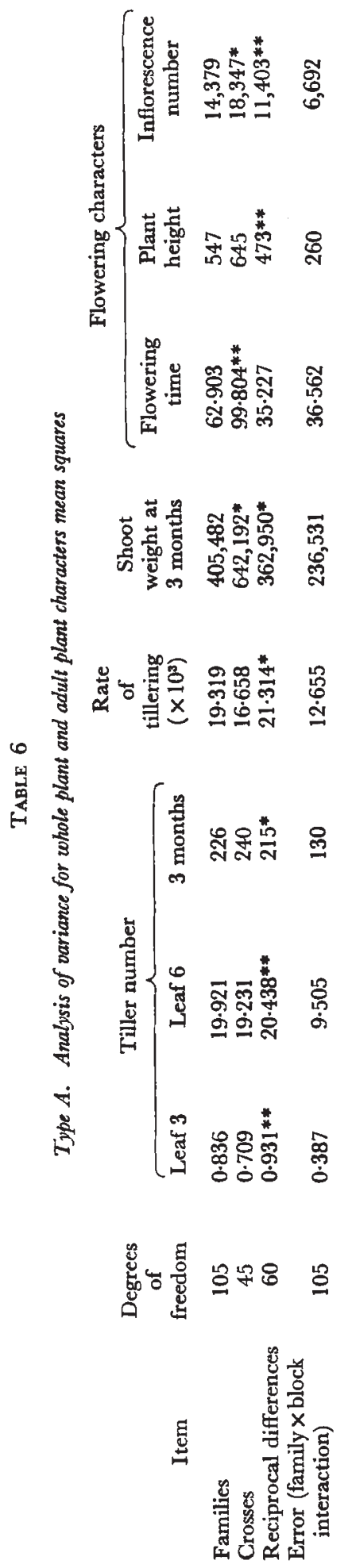


for the other characters was, in general, due to additive maternal effects for tiller characters and for shoot weight at three months, but due to maternal interactions for plant height and spike number (table 8). The genetic effects were generally small and non-additive for this group with the exception of flowering time and spike number. This can be seen from table 9 which presents the components of variance and genetic parameters. Where present the maternal effects (additive plus interactions) again account for less than 10 per cent. of the total phenotypic variance, a proportion which is of approximately the same order of size as the genetic variance.

TABLE 7

Type B. Analysis of variance for flowering time

\begin{tabular}{|c|c|c|}
\hline Item & $\begin{array}{c}\text { Degrees } \\
\text { of } \\
\text { freedom }\end{array}$ & Flowering time \\
\hline $\begin{array}{l}\text { (Males }+ \text { females) } / 2 \\
\text { Males } \times \text { females }\end{array}$ & 60 & $77 \cdot 815^{* *}$ \\
\hline interaction & 30 & $42 \cdot 458$ \\
\hline Error & 105 & $36 \cdot 562$ \\
\hline
\end{tabular}

\section{Discussion}

(i) Maternal effects

The presence of maternal effects in early seedling characters can be expected since environmental influences on seed development will be largely due to the nature of the maternal parent. By the time the seed of Lolium is shed the shoot apex of the embryo has become organised with three or four visible primordia (Sharman, 1947). Furthermore, the initial growth of the newly germinated seedling will be largely dependent on the food reserves in the seed which in turn will be dependent on the maternal phenotypes. Thus the dimensions of the first three or four leaves will be expected to show appreciable maternal effects, as they do in this population. But leaf 6 , on the other hand, is not present as a visible primordium in the mature seed. In addition it develops at a time when the seedling has become well established and likely to be independent of the food reserves in the seed. It is therefore not surprising that while the dimensions of leaf 3 show maternal effects, those of leaf 6 do not.

It is perhaps somewhat surprising that none of the characters representing leaf formation showed maternal effects. While it is easy to see how the rate of appearance of successive leaves between the third and sixth leaves might be independent of maternal influence, the absolute time of formation of the early leaves might have been expected to reflect such events as germination time which in turn is likely to show maternal effects.

Tiller number, on the other hand, shows maternal effects at all stages at which it was measured. Tiller number at any stage of growth is greatly influenced by variation in the node on the main shoot at which the first lateral tiller appeared. If a lateral is produced in the axil of the coleoptile, this rapidly begins to produce secondary tillers in turn. Thus the rate of tillering tends to be logarithmic, up to certain limits which will depend on the environment, and thus the absolute tiller number will be greatly affected by small initial differences. The onset of tillering, and in particular the 

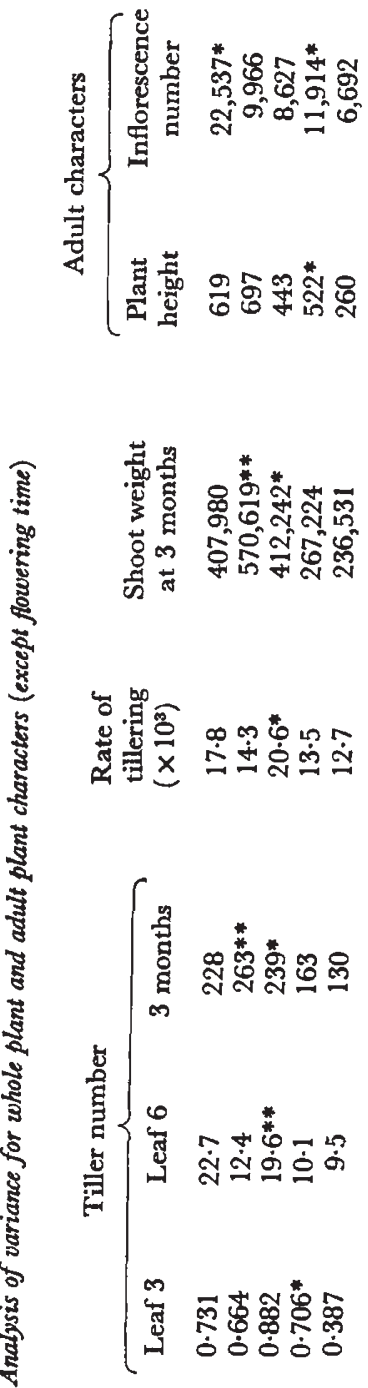

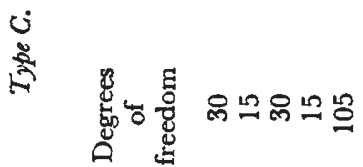

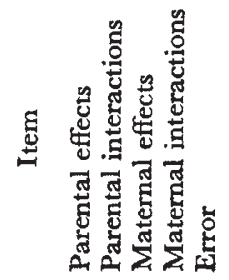




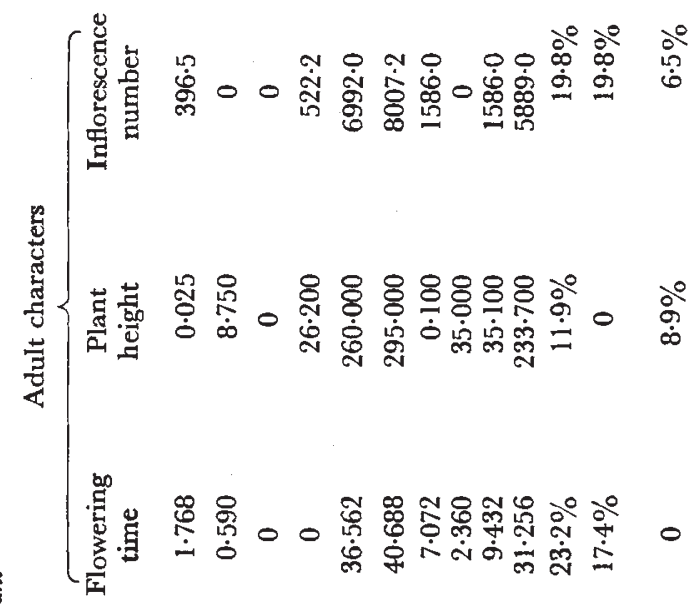

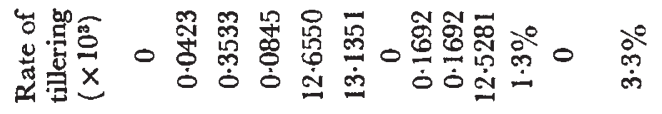

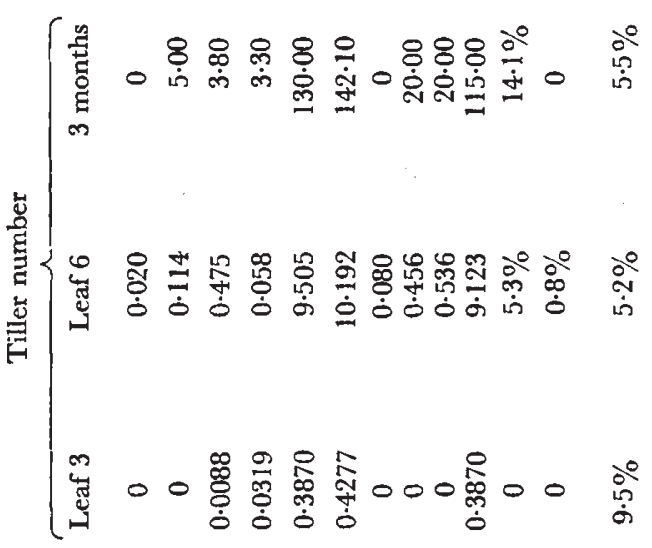

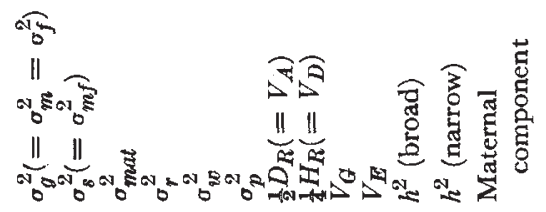


presence or absence of a coleoptile lateral, are known to be greatly influenced by environmental factors such as light and temperature (Mitchell, 1953), and are likely also to be affected by maternal influences such as the formation of seed reserves in the endosperm and possibly by hormonal effects. Thus tiller number may be influenced at an early stage by maternal factors and because of the nature of the tillering process this influence will be perpetuated.

Although there tends to be a negative correlation between tiller number per plant and the average weight of an individual tiller (Edwards and Cooper, 1964), this is not complete and so plants with more tillers tend to have greater total shoot weight. Thus a maternal effect in tiller number at three months from sowing is likely to be reflected in a similar effect on total shoot weight.

So far it has been possible to present a plausible explanation of the existence of maternal effects in terms of the environmental effects of the maternal parent acting via nutritional and perhaps hormonal factors. These effects may well interact with the seedlings own genotype, as is shown by the existence of significant maternal interaction items in some cases, but it is not necessary to postulate maternal or extra-chromosomal inheritance.

On turning to adult plant characters it is not so easy to present similar explanations. Of the three adult plant characters studied in the following year, two (plant height and number of inflorescences per plant) show appreciable maternal effects. These characters are expressed nearly a year after the seeds are germinated and while the calendar time-scale is to some extent irrelevant, carry-over effects due to maternal factors are less likely to show late in a plant's development. However, the number of inflorescences will be related to the number of tillers and may again reflect maternal effects on tiller number which, as we have seen, are likely to be persistent. Furthermore, the number of inflorescences, that, is the number of fertile tillers, will depend on the number of tillers existing on the plant before the onset of the previous winter which will have provided the necessary vernalisation environment (Cooper, 1954). Thus it is again possible (albeit rather tenuously) to explain the existence of maternal effects in inflorescence number as being due to a carry-over of an early nutrition effect.

Finally, plant height shows maternal effects and here it is not easy to see how this might be due to a similar carry-over effect. Other studies in Lolium perenne (Thomas, 1967; Hayward and Breese, 1966) have demonstrated the existence of maternal effects in adult plant characters and so it may be that maternal inheritance through extra-chromosomal agents is involved. In fact, Breese (1966) has argued that an organism like ryegrass which is in nature propagated largely by asexual reproduction may have evolved a system allowing the generation of variation and thus the possibilities of adaptation through an extra-chromosomal mechanism. However, in the present case further studies (Emara, unpublished) have shown that none of the reciprocal differences reported here (whether in young or adult characters) are heritable. So it seems that they all represent maternal effects rather than maternal inheritance although the mechanisms involved remain obscure in the case of plant height.

\section{(ii) Genetic effects and population structure}

Mather $(1943,1960)$ and Breese and Mather (1960) have argued that the nature (and indeed the existence) of the genetic variation in a population 
for a quantitative character will depend upon the type of selection which has operated on the population in the past. Broadly speaking, absence of selection (i.e. a character being neutral) or stabilising selection will be expected to maintain genetic variation of a largely additive nature, while strong directional selection will reduce the total genetic variation which will tend to become composed of non-allelic interactions and unidirectional dominance effects. Of course these expectations will be complicated by variations in mating system and population size, but in the case of the Lolium population which we have been investigating these are unlikely to be important for the population is outbreeding and large and probably is a reasonable approximation to a random mating population. Since, as we have pointed out in the introduction, the management treatments of the population for the past 100 years ( 50 generations) or so are known, it would seem to be suitable material to use to test the validity of Mather's predictions for we can draw some kind of conclusions about the selective forces which have probably operated on these characters in the past. This is rarely possible in natural or semi-natural populations.

Since the seedling leaf characters show, on the whole, both additive and non-additive genetic variation with the additive variation providing an appreciable proportion of the total genetic variation, these characters might appear to have been subjected to no selection or to stabilising selection. We know little about the competitive advantages of these characters in the sward except that very large numbers of plants do not survive the seedling stage (Charles, 1961) and so presumably competition is intense. At first sight it might seem that larger leaves or faster rate of leaf appearance would be competitively advantageous. But in fact there is a strong negative genetic correlation between these two characters (Edwards and Cooper, 1963; Edwards, 1967) and so it may be that the most favourable combination of characters would involve intermediate values of both. This negative correlation is mainly due to an association between leaf length and rate of leaf appearance (Edwards, 1967) and these two characters show the highest proportion of additive variance in the total genetic variance while leaf width, which is not involved in the negative correlation, and absolute dates of leaf appearances have the larger proportions of non-additive variances. The absolute date of leaf appearance in the seedling stage is mainly associated with germination time which is likely to be under strong directional selection.

The various measures of number of tillers and plant size at three months show relatively little total genetic variation and no additive genetic variation. Under sward conditions tiller number will be very important in ensuring vegetative survival. Thus this group of characters will be under strong directional selection and it is expected that only non-additive genetic variation will remain in the population. Of the adult characters, flowering time shows appreciable additive genetic variance. Cooper (1959b) has argued that in the conditions under which this crop has been grown for seed in the past, the taking of a single seed harvest will impose a stabilising selection for flowering time. Thus it is to be expected that additive genetic variation will be present in the population, as was also found by Cooper (1959a) for other similar populations of Lolium perenne. The number of inflorescences per plant also had a very high proportion of additive variance and at first sight this is rather surprising since one might imagine that this 
character would be subject to directional selection. Although no data is available for Lolium, studies in barley and other cereal crops have shown that there is often a negative correlation between the numbers of inflorescences per plant and the number of seeds per inflorescence (Johnson and Aksel, 1959). If this is also the case in Lolium it may be that, as in the case of leaf size and rate of leaf appearance, selection for the individual characters will have been stabilising thus retaining additive variation.

Finally plant height at maturity shows only non-additive variation. It is not easy to see what selection force the management system outlined earlier will have had on this character but presumably taller plants will have been able to receive more light and therefore will have been at an advantage. Thus selection will have had a directional component and the absence of additive variation is not surprising.

In making these somewhat speculative comparisons between past selection for a character and the nature of the genetic variation in the population, it must be recognised that there are two major possible sources of error. Firstly the estimates of the genetic variances may be inaccurate either because they are biassed due to the genetic assumption discussed earlier being invalid or because of sampling errors due to restrictions on the size of the sample. Secondly the deductions from the known management system to the nature of the selective forces may be invalid. Nevertheless, there exist in general the relationships which Mather's hypothesis predicted: namely that characters which have had no selection or stabilising selection would show appreciable additive genetic variation while those on which directional selection had been predominant would show mainly non-additive variation.

\section{Summary}

1. A population of Lolium multiflorum was sampled and the genetic variation in the sample of 60 plants was analysed using a North Carolina design II mating scheme (Comstock and Robinson, 1952). A number of seedling leaf, tiller number, and adult flowering characters were recorded.

2. Reciprocal crosses showed that reciprocal differences existed for early seedling leaf characters (leaf 3 dimensions) for all tiller number characters and for plant height and inflorescence number at maturity.

3. These seemed to be due to maternal effects rather than maternal inheritance and those which appeared unexpectedly late in development could be explained as carry-overs of early effects.

4. There was appreciable genetic variation present for all seedling leaf characters and for flowering time and inflorescence number, but little for any tillering character or for plant height at maturity.

5. The nature of this genetic variation was analysed in relation to the probable selective forces acting on each character for the past 100 years or so. The nature of these forces was deduced from the known management history of this population in agriculture.

6. In general, characters which might be expected to have been subjected to stabilising selection show a fairly high proportion of additive genetic variation (seedling leaf characters, flowering time and inflorescence number), while those expected to have been selected directionally show a high proportion of non-additive genetic variation (all tiller characters and plant height). 


\section{REFERENCES}

Beddows, A. R. 1953. The ryegrasses in British agriculture: a survey. Bull. Welsh Pl. Breed. Sta. Series H, No. 17, $41-52$.

BEDDOWS, A. R., BREESE, E. L., AND LEWIS, B. 1962. The genetic assessment of heterozygous breeding material by means of a diallel cross. 1. Description of parents, self and cross fertility and early seedling vigour. Heredity, 17, 501-513.

BREESE, E. L. 1966. Reproduction in ryegrass. Paper presented to "Conference on Reproductive Biology and Taxonomy of Vascular Plants". B.S.B.1.

BREESE, F. L., AND MATHER, K. 1960. The organisation of polygenic activity within a chromosome in Drosophila. Heredity, 14, 375-399.

Charles, A. н. 1961. Differential survival of grass cultivars of Lolium, Dactylis and Phleum. J. Brit. Grassl. Soc., 16, 69-75.

COMSTOCK, R. E., AND ROBINSON, H. F. 1952. Estimation of average dominance of genes. In Heterosis, ed. J. W. Gowen, Ames, Iowa State College Press. pp. 494-516.

COOPER, J. P. 1954. Studies on growth and development in Lolium. IV. Genetic control of heading responses in local populations. J. Ecol., 42, 521-556.

COOPER, J. P. 1959a. Selection and population structure in Lolium. II. Genetic control of date of ear emergence. Heredity, 13, 445-459.

COOPER, J. P. 1959b. Selection and population structure in Lolium. III. Selection for date of ear emergence. Heredity, 13, 461-479.

COOPER, J. P., AND EDWARDs, K. J. R. 1961. The genetic control of leaf development in Lolium. 1. Assessment of genetic variation. Heredity, 16, 63-82.

EDWARDS, K. J. R., AND COOPER, J. P. 1963. The genetic control of leaf development in Lolium. 2. Response to selection. Heredity, 18, 307-317.

EDWARDs, K. J. R. 1967. Developmental genetics of leaf formation in Lolium. 2. Analysis of selection lines. Genet. Res., 9, 247-257.

HAYWARD, M. D., AND BRFESE, E. L. 1966. The genetic organisation of natural populations of Lolium perenne. 1. Seed and seedling characters. Heredity, 21, 787-304.

JENKIN, T. J. 1931. Methods and technique of selection, breeding and strain-building in grass. Bull. Bur. Pl. Gen. Aberystwyth, 3, 5-34.

JOHNSON, L. P. V., AND ASKEL, R. 1959. Inheritance of yielding capacity in a fifteen-parent diallel cross of barley. Can. J. Genet. Cytol., 1, 208-265.

KEARSEY, M. J. 1965. Biometrical analysis of a random mating population: Comparison of five experimental designs. Heredity, 20, 205-235.

MATHER, K. 1943. Polygenic inheritance and natural selection. Biol. Revs., 18, 32-64.

MATHER, K. 1960. Evolution in polygenic systems. Evolutzione e genetica, 47, 131-152.

MITCHELL, K. J. 1953. Influence of light and temperature on growth of ryegrass (Lolium spp.). 1. Pattern of vegetative development. Physiol. Plant., 6, 21-46.

Sharman, B. c. 1947. The biology and developmental morphology of the shoot apex in the Gramineae. New Phytol., 46, 20-34.

THOMAs, R. L. 1967. Inter-populational variation in perennial ryegrass. 1. Population means. Heredity, 22, 481-498. 